\title{
Fallot Tetralojili Olguların Preoperatif Değerlendirilmesinde BT Anjiyografinin Önemi; Tek Merkez Deneyimi
}

\author{
Importance of CT Angiography in Preoperative Evaluation of \\ Patients With Tetralogy of Fallot; Single Center Experience
}

\author{
${ }^{1}$ Tülay Demircan, ${ }^{2}$ Onur Işı1k, ${ }^{2}$ Muhammet Akyüz, ${ }^{3}$ Dilek Öncel, ${ }^{1}$ Ali Rahmi Bakiler \\ ${ }^{1}$ Sağlık Bilimleri Üniversitesi Tepecik Eğitim ve Araştırma Hastanesi Pediyatrik Kardiyoloji, \\ İzmir, Türkiye \\ ${ }^{2}$ Sağlık Bilimleri Üniversitesi Tepecik Eğitim ve Araştırma Hastanesi \\ Pediyatrik Kalp ve Damar Cerrahisi, İzmir, Türkiye \\ ${ }^{3}$ Sağlık Bilimleri Üniversitesi Tepecik Eğitim ve Araştırma Hastanesi Radyoloji, İzmir, Türkiye
}

Özet: Çalışmamızda Fallot tetralojili olgularda koroner ve pulmoner arter anomalileri ve eşlik eden ekstrakardiyak malformasyonların değerlendirilmesinde Bilgisayarlı Tomografi (BT) anjiyografinin tanısal önemi araştırıldı. Ayrıca operasyon öncesi çekilen BT anjiyografinin cerrahi açıdan faydalarını değerlendirmeyi amaçladık. Ocak 2016- Ocak 2018 tarihleri arasında Fallot tetralojisi (pulmoner kapak yokluklu ve pulmoner atrezili dahil) tanısı konulan olguların dosyaları geriye dönük olarak incelendi. Bilgisayarlı Tomografi anjiyografi çekilmemiș olanlar ve dosyasında eksik veri bulunanlar çalıșmaya dahil edilmedi. Hastaların yaşı, cinsiyeti, operasyon yaşı, ekokardiyografi, BT anjiyografi ve operasyon sonuçları değerlendirildi. Toplam 32 hasta çalışmaya alındı. Ortalama yaşları $18 \pm 17$ (1-84) ay idi. 32 hastanın 6'sında pulmoner kapak atrezili ve 1 olguda pulmoner kapak yokluklu Fallot tetralojisi vardı. BT anjiyografi ile saptadığımız ekstrakardiyak malformasyonlar 6 olguda aortopulmoner kolleteral arter, 2 olguda retroaortik seyirli inominate ven, 1 olguda aberran sağ subklavian arter ve 1olguda koroner arter anomalisi idi. Fallot tetralojili hastalarda pulmoner arterlerin konfluensi, çapları ve aortopulmoner kolleteral arter gibi vasküler yapıları göstermede BT anjiyografi önemlidir. Bu inceleme cerrahi seçimi ve yaklaşım açısından belirgin fayda sağlamaktadır.

Anahtar Kelimeler: fallot tetralojisi, bilgisayarlı tomografi, cerrahi onarım, ekstrakardiyak

\begin{abstract}
The aim of this study is to investigate the diagnostic significance of Computerized Tomography (CT) angiography in the evaluation of coronary and pulmonary artery anomalies and accompanying extracardiac structures in pediatric patients with tetralogy of Fallot. We also aimed to evaluate the surgical benefits of CT angiography performed before operation. The data of patients with operated tetralogy of Fallot and variants were retrospectively reviewed between January 2016- January 2018. Patients without CT angiography examination and cases with missing data were not included in the study. The age, gender, age at diagnosis, echocardiography and CT angiography and operation procedure were evaluated. A total of 32 patients were included in the study. The mean age of the patients was $18 \pm 17$ (1-84) months. Of the patients, 6 had Tetralogy of Fallot with pulmonary atresia and 1 had tetralogy of Fallot without pulmonary valve. The extracardiac malformations detected by CT anjiography were aortopulmonary collateral artery in 6 patients, retroaortic innominate ven in 2 patients, aberrant right subclavian artery in 1 patient and coronary artery anomaly in 1 patient. CT angiography is important in patients with tetralogy of Fallot showing concomitant pulmonary artery confluence, diameter and aortopulmonary collateral artery. This examination provides significant benefits in terms of surgical choice and approach.
\end{abstract}

Keywords: tetralogy of Fallot, computerized tomography, cardiac surgery, extracardiac

ORCID ID of the authors: T D 0000-0002-2529-2906, O I 0000-0002-5555-563X, M A 0000-0002-5555-564X, D Ö 0000-0001-5341-5558, A R B 0000-0001-8234-3071

Received 22.06.2019

Accepted 30.07.2019

Online published $\quad 31.07 .2019$

Correspondence: Tülay DEMİRCAN- Sağlı Bilimleri Üniversitesi Tepecik Eğitim ve Araştırma Hastanesi Pediyatrik Kardiyoloji, İzmir/Türkiye e-mail: tulay.sirin@hotmail.com 


\section{Giriş}

Fallot tetralojisi en sik görülen siyanotik konjenital kalp hastalığıdır ve tüm konjenital kalp hastalıklarının \%5-7'sini oluşturur (1). Ventriküler septal defekt, sağ ventrikül çıkış yolu obstrüksiyonu, aortik kökün ventriküler septumun üzerine ata biner tarzda yerleşimi ve sağ ventrikül hipertrofisi hastalığın dört major kriteridir (2,3). Fallot tetralojisinin en önemli özelliği sağ ventrikül çıkım yolunun öne ve sola deviyasyonu ile oluşan subpulmonik darlıktır. Hafif formlarında darlık sadece sağ ventrikül infundibulumunda iken ağır formlarında pulmoner kapak atrezik olabilmektedir $(3,4)$. Tedavi edilmediği taktirde hastaların sadece \%10'u 20'li yaşlara ulaşabilmektedir (5). Bu hastalar bir veya daha fazla aşamalı tedavi yaklaşımları ile rezidüel lezyonlar ve uzun dönem komplikasyonlar olsa bile kaliteli yaşam koşulları ve uzun yaşam sürelerine sahip olabilmektedirler. İlk tanımlandığ dönemlerde palyasyon ağırlıklı anlayış benimsenmiş iken günümüzde daha erken düzeltme ameliyatları öne çıkmıştır $(6,7)$.

Tanı koyma araçları tek başına transtorasik ekokardiyografi (TTE) olabileceği gibi hastanın yaşına, kliniğine, merkezin deneyimine bağlı olarak daha fazla görüntüleme yönteminin kombinasyonu şeklinde de olabilir. Önceleri katater anjiyografi Fallot tetralojisi ameliyatından önce vazgeçilmez bir tanı metodu idi. Teknolojik gelişime paralel olarak bilgisayarlı tomografi anjiografi (BT) ve manyetik rezonans (MR) anjiyografinin yaygınlaşmasına bağlı olarak günümüzde tanısal amaçlı katater anjiyografi daha az tercih edilmektedir (8). Merkezimizde gerekli olan olgulara TTE yanında BT anjiyografi çekilmektedir. Çalışmamızda Fallot tetralojisi tan1l1 olgulardan operasyon öncesi BT anjiyografi çekilmiş olanların dosyaları geriye dönük olarak değerlendirildi. Burada saptanan ek anomalilerin operasyon esnasindaki cerrahi katkıları gözden geçirildi.

\section{Metaryal ve Metod}

2016 Ocak ve 2018 Ocak ayı tarihleri arasında hastanemizde Fallot tetralojisi (pulmoner kapak yokluklu ve pulmoner atrezili dahil) tanıs1 ile operasyon öncesinde BT anjiyografi çekilen hastaların dosyaları geriye dönük olarak incelendi. Hastaların yaşı, cinsiyeti, vücut ağırlığı, oda havasındaki arteriyel oksijen saturasyonu, eşlik eden anomalileri, TTE ve BT anjiyografi bulguları, ameliyat prosedürü ve ameliyatta saptanan ek bulguları değerlendirildi. BT anjiyografi tetkiki olmayan ve dosyasında eksik veri bulunan olgular çalışmaya dahil edilmedi. Çalışma öncesi hastane etik kurulundan onay alındı. Ekokardiyografi raporlarından ventriküler septal defekt (VSD), aortanın pozisyonu, sağ ventrikül çıkım yolu, pulmoner arterlerin çapları, eşlik eden atriyal septal defekt (ASD), patent duktus arteriozus (PDA) ve koroner arter çıkışları sonuçları değerlendirildi.

Bilgisayarli tomografi anjiyografi Siemens Defination AS 128 kesit cihaz (kolimasyon 16x1.25 mm, dilim kalınlığ $0,75 \mathrm{~mm}$, dilim aralığ $10,625 \mathrm{~mm}$, ayar aralığ 1 otomatik, yeniden yapılandırma aralığı $0.625 \mathrm{~mm}$ ) ile yapıldı. Vücut alanına göre 'care doz' teknolojisi kullanılarak dokuya göre en düşük doz radyasyon kullanildi. $\mathrm{Bu}$ doz yenidoğanlarda yaklaşık 2 direk grafi dozu toplamı idi. Tanısal değerlendirme amaciyla pulmoner darlığın yeri (valvüler, infindibuler ve supravalvuler), koroner arterler, aortopulmoner kolleteral arterler ve ekstravasküler yapılar radyolog, pediyatrik kardiyolog ve pediyatrik kalp cerrahı tarafından değerlendirildi.

İstatistiksel analiz için Statistical Package for Social Sciences for Windows, version 21.0 software (SPSS Inc, Chicago IL, USA) kullanıldı. Sonuçlar ortalama \pm standart sapma, kategorik değişkenler yüzde şeklinde ifade edildi. Tanımlayıcı parametreler olan sıklık, yüzde ve ortalama \pm standart sapma için deskriptif istatistik kullanıldı.

\section{Bulgular}

Fallot tetralojisi tanıs1 ile ameliyat edilen 52 hasta verisine ulaşıldı. Bunlardan TTE ve BT anjiografi tetkikleri ile değerlendirme sonrası ameliyat edilen toplam 32 hasta çalışmaya 
dahil edildi. Hastaların yaşları $18 \pm 17$ (1-84) ay, \% 65'i kız ve \%35'i erkek idi. Ortalama vücut ağırlığı $8,7 \pm 2,8 \quad(3,5-17) \quad \mathrm{kg}$, oda havasında oksijen saturasyonu \% 83 7,6 (6590), Mc Goon oran1 1,8 $\pm 0,3$ (1-2,4) idi. Genetik anormallik tanısı alan hasta oran1 \%18 idi. Bunların 2'si DiGeorge sendromu, 2'si VACTERL (vertebral kusurlar, anal atrezi, kardiyak malformasyonlar, trakeaözafageal fistül, renal anomaliler ve ekstremite anomalileri), 1'i Down sendromlu ve 1'i intrakranial kavernöz hemanjiyom idi. Bir hastamızın annesinde de Fallot tetralojisi tanis1 mevcuttu.

Hastaların 6's1 pulmoner atrezili ve 1'i pulmoner kapak yokluklu Fallot tetralojisi tanılıydı ve 11'ine ASD, 7'sine PDA eşlik ediyordu. BT ile saptadığımız ekstrakardiyak malformasyonlar 6 olguda geniş aortopulmoner kolleteral arter, 6 olguda sol pulmoner arter darlığ 1,2 olguda retroaortik seyirli inominate ven, 1 olguda aberran sağ subklavian arter (ARSA) ve 1 olguda sağ koroner arter çıkışlı sol koroner arter idi (tablo1).

Operasyonda tespit edilen ek tanılar; 12 hastada pulmoner kapakta displazi-biküspit açılım, 1 hastada çatısız koroner sinüs, 1 hastada konjenital perikardiyal defekt ve 1 hastada da sol brakiosefalik arterde dallanma anomalisi idi (tablo1). Hastalardan tam düzeltme ameliyatına uygun bulunmayan 8 olguya median sternotomi insizyonu ile modifiye BT şant yapıldı. Fallot tetralojili şant yapılan tüm olgulara izlemde tam düzeltme operasyonu yapildi. Pulmoner atrezi olan 4 olguya da kapaklı kondüit kullanılarak tam düzeltme ameliyatı yapıldı.

Tablo 1. TTE, BT anjiyografi ve cerrahide saptanan ekstrakardiyak anomaliler

\begin{tabular}{|c|c|c|c|c|c|c|c|c|c|}
\hline & $\begin{array}{c}\text { Ars } \\
\mathbf{a}\end{array}$ & $\begin{array}{c}\text { Map } \\
\text { ka }\end{array}$ & $\begin{array}{l}\text { Sağ } \\
\text { arkus } \\
\text { aorta }\end{array}$ & PSSVK & $\begin{array}{l}\text { Retroaortik } \\
\text { innominate } \\
\text { ven }\end{array}$ & $\begin{array}{l}\text { Pulmoner } \\
\text { kapakta } \\
\text { displazi- } \\
\text { bikasp }\end{array}$ & $\begin{array}{l}\text { Çatısız } \\
\text { korone } \\
\text { r sinüs }\end{array}$ & $\begin{array}{l}\text { Konjenital } \\
\text { perikardiyal } \\
\text { defekt }\end{array}$ & $\begin{array}{l}\text { Sol } \\
\text { brakiosefalik } \\
\text { arterde } \\
\text { dallanma } \\
\text { anomalisi }\end{array}$ \\
\hline EKO & & & 9 & 1 & 0 & & & & \\
\hline $\begin{array}{l}\text { BT } \\
\text { anjiyografi }\end{array}$ & 1 & 6 & 9 & 2 & 2 & & & & \\
\hline Cerrahi & & & 9 & 2 & 2 & 12 & 1 & 1 & 1 \\
\hline
\end{tabular}

TTE: Transtorasik Ekokardiyografi, BT: bilgisayarlı tomografi, ARSA: Aberran să̆ subklavian arter, persistan sol superior vena kava (PSSVK), APKA: Aortopulmoner kolleteral arter

\section{Tartışma}

Fallot tetralojisi operasyonlarından önce pulmoner arterlerin çapları, periferik dallarında darlık olup olmadığı, infindibuler darlıklar, ek VSD, ASD varlı̆̆ 1 , koroner arterlerin çıkış ve seyirleri, aortopulmoner kolleteral arterler ve bunların boyutları, sağ ventrikül, sol ventrikül boyut ve fonksiyonları ve triküspit-mitral kapak gibi kardiyak yapıların ayrıntılı değerlendirilmesi gerekmektedir. Transtorasik EKO preoperatif kardiyak anatomiyi değerlendirmede çoğu zaman yeterli olmaktadır fakat ekstrakardiyak yapıları göstermede kısıtlılıkları vardır. Katater anjiyografi, MR anjiyografi ve BT anjiyografi avantaj ve dezavantajları ile ek görüntüleme yöntemi olarak kullanılmaktadır. Katater anjiyografi, hemodinamik veriler yanında vasküler anatomiyi göstermektedir ve aortopulmoner kolleteral arter embolizasyonu için yararlı vasküler erişim sağlayabilir. Fakat sedasyon ihtiyacinın fazla olmas1, kontrast madde gereksinimi, hemoraji, spell ataklarını tetikleyebilmesi ve enfeksiyon riskinin artmas1 nedeniyle çocuklarda günümüzde daha az tercih edilir olmuştur. Manyetik rezonans görüntülemenin ise uzun sürmesi, sedasyon ihtiyacının fazla olması ve küçük damarsal yapıları göstermede yetersiz kalması 
gibi dezavantajları vardır. Bilgisayarlı tomografi anjiyografi kısa süreli olması, genel durumu bozuk hastalarda da uygulanabilmesi, yeni geliştirilen teknolojilerle radyasyon maruziyetinin azaltılması ile günümüzde sık kullanılan yöntemlerden olmuştur (9). Ayrıca BT anjiyografi ile pulmoner damar yatağ koroner arterler, aortopulmoner kolleteraller, ekstrakardiyak vasküler yapılar ve trakeobronşiyal ağaç da iyi görüntülenebilir $(10,11)$. Çalışmamızda TTE ile saptanamayan ekstrakardiyak vasküler patolojiler BT anjiyografi ile saptand 1 ve cerrahi planlamada BT anjiyografinin yol gösterici olduğu görüldü. Hastalarımızda saptadığımız ARSA, retroaortik innominate ven, aortopulmoner kolleteral arter ve sol pulmoner arterde \%20 oranında duktus arteriozusun kapanması ile oluşan darlık tanılarının tümü BT anjiyografi ile konulmuş olup cerrah tarafindan operasyonda bu tanı doğrulanmıştır. Fallot tetralojili olguların yaklaşık \%25'inde genellikle ayna görüntüsünde bir sağ aortik ark görülür. Atriyal septal defekt $\% 5$ ve sol persistan süperior vena kava ise $\% 11$ oranında görülür (12). Çalışmamızda sağ arkus aorta $\% 31$ oranında saptanmıs olup hepsi TTE ve BT anjiyografide görülmüştür. İki hastamızda BT anjiyografi ile saptadığımız retroaortik innominate ven nadir görülen bir sistemik venöz dönüş anomalisidir. $\mathrm{Bu}$ hastalarda innominate ven asendan aortanın posteriorunda seyrederek superior vena kavanın proksimal segmentine bağlanır. $\mathrm{Bu}$ hastalarda anatomiye hakim olmak ve venöz kanülasyon stratejisini belirlemek adına önemli olabilir (13). Fallot tetralojili olgularda daha s1k görülen bu ekstrakardiyak vasküler malformasyonlar cerrahi ve gec dönem izlem planlarını etkileyebilmektedir $(14,15)$.

Koroner arter anomalileri bu grup hastaların \%5'inde görülür $(16,17)$. Cerrahi prosedürü en sik etkileyen anomali, sol ön

\section{KAYNAKLAR}

1. Cuypers JA, Menting ME, Konings EE, Opic P, Utens EM, Helbing WA, et al. Unnatural history of tetralogy of Fallot: prospective follow-up of 40 years after surgical correction. Circulation. 2014;130:1944-1953. inen koroner arterin anormal olarak să koroner arterden çıkıp sağ ventrikül çıkım yolunu çaprazlayarak seyretmesidir $(17,18)$. Hastalarımızdan 1 tanesinde sol koroner arterin sağdan çıktığını gözlemledik sağ ventrikül çıkım yolunu çaprazlamadığ 1 için cerrahi açıdan risk oluşturmadı.

Fallot tetralojili hastalarda tam düzeltme veya şant ameliyatı seçiminde McGoon oran1 (normali 2-2,5 arasi), Nakata indeksi (normali $300 \pm 30 \mathrm{~mm}^{2} / \mathrm{m}^{2}$ ), sol ventrikül hacminin aortaya oranı ve pulmoner anulus $\mathrm{Z}$ skoru kullanılmaktadır (19). BT anjiyografi ile periferik pulmoner arter anomalileri, Mc Goon oranı ve pulmoner anulus iyi değerlendirildiği için şant veya tam düzeltme operasyonu seçiminde oldukça yararlı olmuştur. Tam düzeltmeye uygun Mc Goon değerleri hesaplanan hastalarda da pulmoner anulus ve pulmoner anulus $\mathrm{Z}$ skoru preoperatif ölçümlerde değerlendirilmiş ve transanüler yama gereksinimi olup olmadiğ 1 kararı alınabilmiştir. $\mathrm{Bu}$ durum pulmoner kapak rekonstrüksiyonu planlanmasında cerrahi konfor sağlamaktadır. Tomografi ve MR tetkiklerinin ulaşılabilirliğinin artmasıyla özellikle BT anjiyografinin klinik faydalarının merkezler tarafindan tecrübe edilmesinin de desteğiyle basınç ölçümü gerekmeyen, girişimsel bir planın olmadığı hastalarda bu görüntüleme yöntemlerinin invaziv katater anjiografinin yerini alacağını düşünmekteyiz. Ekokardiyografi cihazlarındaki gelișmelerle ve yapan kişilerin deneyiminin artması ile, ayrica BT anjiyografinin de bu alanda kullanıma girmesi ile birlikte Fallot tetralojili olgularda yeterli bilgi sağlanabilmektedir.

Sonuç olarak gerekli olan olgularda ekstrakardiyak anomalileri göstermede BT anjiyografinin operasyon öncesi yararlı olabileceği görülmüştür. Çalışmamızda vaka sayısı az olup daha büyük vaka serili çalışmalara ihtiyaç duyulmaktadır. 
defect ("Eisenmenger VSD") International Journal of Cardiology. 1989;9:341-355

3. Anderson RH, Weinberg PM. The clinical anatomy of tetralogy of Fallot. Cardiology in the Young. 2005;15:38-47

4. Van Praagh R. The first Stella Van Praagh memorial lecture:the history and anatomy of tetralogy of Fallot. Seminars in Thoracic Cardiovascular Surgery. Pediatric Cardiac Surgery Annual 2009;12:19-38.

5. Freedom RM, Yoo SJ. Tetralogy of Fallot. In: Freedom RM, Yoo SJ, Mikailian H, Williams WG, eds. The natural and modified history of congenital heart disease. New York: Futura; 2004. p.186-211.

6. Van Arsdell GS, Maharaj GS, Tom J, Rao VK, Coles JG, Freedom RM, et.al.What is the optimal age for repair of tetralogy of Fallot? Circulation. 2000;102:123-129.

7. Sandoval JP, Chaturvedi RR, Benson L, Morgan G, Van Arsdell G, Honjo O,et al. Right ventricular outflow tract stenting in tetralogy of Fallot infants with risk factors for early primary repair. Circulation Cardiovasc Intervention. 2016;9:3979.

8. Ntsinjana HN, Hughes ML, Taylor AM. The role of cardiovascular magnetic resonance in pediatric congenital heart disease. Journal of Cardiovascular Magnetic Resonance 2011;13:51.

9. Ou P, Celermajer DS, Calcagni G, Brunelle F, Bonnet D, Sidi D. Three-dimensional CT scanning: a new diagnostic modality in congenital heart disease. Heart 2007; 93:908913

10. Siegel MJ. Multiplanar and three-dimensional multi-detectorrow CT of thoracic vessels and airways in the pediatric popu-lation. Radiology. 2003;229:641-50.

11. Driessen MM, Breur JM, Budde RP, et al. Advances in cardiac magnetic resonance imaging of congenital heart disease. Pediatric Radiology. 2015;45:5-19.
12. Kouchoukos NT, Blackstone EH, Doty DB. Ventricular septal defect with pulmonary stenosis or atresia.In Kirklin/Barratt-Boyes (eds) Cardiac Surgery, 3rd edn. Churchhill Livingstone, Philadelphia. 2003. p. 946-1073.

13. Yilmaz M, Sargon MF, Dogan OF, Pasaoglu I. A very rare anatomic variation of the left brachiocephalic vein: Left retro-aortic brachiocephalic vein with tetralogy of Fallot. Surgical and Radioogicl Anatomy. 2003;25:158-60

14. Siripornpitak S, Pornkul R, Khowsathit P, Layangool T, Promphan W, Pongpanich B, Cardiac CT. Angiography in children with congenital heart disease. European Journal of Radiology. 2013;82:1067-82.

15. Dillman JR, Hernandez RJ. Role of CT in the evaluation of congenital cardiovascular disease in children. AJR American Journal of Roentgenology. 2009;192:1219-31.

16. Frank L, Dillman JR, Parish V, et al. Cardiovascular MR imaging of conotruncal anomalies. Radiographics. 2010;30:1069-94.

17. Vastel-Amzallag C, Le Bret E, Paul JF, Lambert V, Rohnean A, El Fassy E, et al. Diagnostic accuracy of dual-source multislice computed tomographic analysis for the preoperative detection of coronary artery anomalies in 100 patients with tetralogy of Fallot. Journal Thoracic and Cardiovasculary Surgery. 2011;142:120-6.

18. Hrusca A, Rachisan AL, Gach P, Pico H, Sorensen C, Bonello B, et al. Detection of pulmonary and coronary artery anomalies in tetralogy of Fallot using non-ECG-gated CT angiography. Diagnostic and Interventional Imaging 2016;97:543-548

19. Özdemir R, Öner T, Demirpençe S, Karadeniz C, Y1lmazer M, Önder Doksöz et al. Fallot tetralojili olgularda tam düzeltme ameliyatı öncesi pulmoner arter gelişim indekslerini etkileyen faktörler: 100 olguda retrospektif gözlemsel bir değerlendirme İzmir Dr. Behçet Uz Çocuk Hastanesi Dergisi. 2015;5:120-124 